Kalpa Publications in Engineering
Volume 1, 2017, Pages 239-245
$\begin{aligned} & \text { ICRISET2017. International Conference on Re- } \\ & \text { search and Innovations in Science, Engineering } \\ & \text { \&Technology. Selected Papers in Engineering }\end{aligned}$

\title{
Optimum Selection of Mechanical Drives Using TOPSIS
}

\author{
Ketan Tamboli ${ }^{1}$, P M George ${ }^{2}$ \\ ${ }^{1}$ Mechatronics Engg. Deptt.,G H Patel College of Engg. \& Tech.,V V Nagar,Gujarat,India,388120 \\ ${ }^{2}$ Mechanical Engg. Deptt.,B V M Engg College,V V Nagar,Gujarat,India,388120
}

\begin{abstract}
New product development demands the analysis of each of the component from various engineering concepts.If a machine is expected to have a mechanical power transmission system, obviously number of options can be thought of.The power transmission system involves many hardware and many options are available.These mechanical drives are expected to be light,energy efficient and maintenance free. In the present work, a data matrix comprising of 10 attributes and 10 alternatives is presented .It is then operated for optimum selection in form of ramking using one of the welknown Multi Attribute Decision Making( MADM) method called Technique for Order Preference by Similarity to Ideal Solution (TOPSIS).The results are given as ranking for the purpose of selectionwhich sets initiative for preliminary design.However the approach presented is also useful for existing designs which needs to be changed to enhance performance.
\end{abstract}

Keywords-Mechanical drives, TOPSIS,MADM

\section{INTRODUCTION}

The present scenario in industrial environment is highly concerned the conservation of energy in one form or other. With the increasing demand for energy due to rapid industrialization, it has become necessary to relook into energy consumptions for any industrial unit. The generation and transmission of power is highly costly and hence the end product becomes uneconomical. The power transmission especially for the mechanical drives need to be attended consciously for the purpose of its effectiveness. In the present times, due to developments in computer hardware and software technology, it is possible to calculate and decide the best suitable choice for the mechanical drives. Number of researchers have used MADM methods such as SAW(Simple Additive Weight )method[1],AHP(Analytical Heirarchy Process)method[2,3],Modified TOPSIS method[4] and VIKOR(VIsekriterijumsko KOmpromisno Rangirange ) [3]. In the present work, TOPSIS (Technique for Order Preference by Similarity to Ideal Solution) method is used for optimally selecting the best drive.Many researchers $[5,6,7,8,9,10,11]$ have used MADM methods for various applications such as for optimal selection of materials etc.

A. Shukla, J.M. Patel, P.D. Solanki, K.B. Judal, R.K. Shukla, R.A. Thakkar, N.P. Gajjar, N.J. Kothari, S. Saha, S.K. Joshi, S.R. Joshi, P. Darji, S. Dambhare, B.R. Parekh, P.M. George, A.M. Trivedi, T.D. Pawar, M.B. Shah, V.J. Patel, M.S. Holia, R.P. Mehta, J.M. Rathod, B.C. Goradiya and D.K. Patel (eds.), ICRISET2017 (Kalpa Publications in Engineering, vol. 1), pp. 239-245 


\section{JUSTIFICATION FOR SELECTION OF DRIVE}

In mechanical drives, number of factors (attributes) are associated with each drive such as center distance, power transmitting capacity, speed ratio, working conditions (temperature range), corrosive atmosphere, etc.), maintenance (lubrication, vibration, noise, etc.). the conflicting requirements of different attributes when number of choices (options/alternatives) are available emphasizes the need of a scientific approach to select the optimum choice. The attributes considered are important from performance, life and maintenance point of view.As an example the minimum centre distance is offerd by gear drive with more power transmitting capacity but has more cost .The contradictory matters related to all attributes compels the use of scientific approach for optimum selection.

\section{DEVELOPMENT OF DATA MATRIX}

A large number of sources $[12,13,14,15,16,17,18]$ are referred to compile the information for various mechanical drives and their attributes, which is represented in Table 1 of Appendix as a $10 \times 10$ matrix, known as data matrix. It is assumed that all the alternatives are possible to be used in a perticular application. The fuzzy attributes are categorised on 1-5 scale and its consideration is taken in the method.The beneficial and nonbeneficial attributes are to be desired for higher and lower values respectively.

\section{MADM METHODS AND TOPSIS}

Following description summarizes about TOPSIS, a wellknown MADM method used for the present work. The mathematical procedural steps are detailed here.The relative weights as required in TOPSIS are decided based on the importance of a particular over other attributes which will give adequate performance of the system with minimum maintenance and repair. However, depending upon the requirement of particular application, these weights could vary and group of experienced designers can decide upon them. Also, in the literature [1] the five point and eleven point scale is suggested which can be used as subjective measure of each attribute. In the present case, the relative weight vector used for all the methods is kept same i.e. is $0.15,0.20$, $0.20,0.10,0.05,0.10,0.05,0.05,0.05,0.05$. The computer codes in MATLAB are developed for all of these methods. The codes are verified with the existing results of other application in the literature and then applied for the present case.

\section{A. TOPSIS Algorithm}

The TOPSIS method was developed by Hwang and Yoon [19].The steps are shown below.

Step 1. Formulation of the Data Matrix

The data matrix comprises of alternatives and attributes for each of them. Thus an element $a[i, j]$ of the data matrix $A$ gives the value of the $\mathrm{j}^{\text {th }}$ attribute in a non-normalized form/units, for the $\mathrm{i}^{\text {th }}$ alternative. Therefore for $m$ alternatives with $n$ pertinent attributes, the data matrix is an $m \times n$ matrix.

Step 2. Relative Importance Matrix Formulation

In case an expert system is being used, this may also be supplied by a panel of experts. This information is stored in an $\mathrm{n} \times \mathrm{n}$ matrix, say $\mathrm{R}$, with all its diagonal elements as unity.

Step 3. Formulation of Normalized Data Matrix

Since all the attributes are with different units it is not possible to compare them.Hence a normalization is done as per below. 


$$
n(i, j)=\frac{a(i, j)}{\sum_{i=1}^{m}(a(i, j))^{2}} .
$$

Step 4. Eigenvalue Formulation

In step 2, the information is stored in a pair-wise basis. Thus if

$$
r_{i j}=\frac{\text { importance of the } i^{\text {th }} \text { attribute }}{\text { importance of the } j^{\text {th }} \text { attribute }}
$$

then ideally

$$
r_{i j}=\frac{r_{i k}}{r_{k j}} .
$$

To overcome the human inconsistency, a drawback, the eigenvalue method is employed. This method seeks to find a weight matrix vector, $\mathrm{W}$, where:

$$
\mathrm{RW}=\lambda \mathrm{W}
$$

and

From above equation we have:

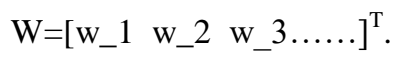

$$
(\mathrm{R}-\lambda \mathrm{I}) \mathrm{W}=0
$$

To avoid the trivial solution,

$$
|R-\lambda I|=0
$$

The solution of equation (4)gives the complete eigen spectrum which is the invariant of 'Attribute Relative Importance Matrix System'. The solution of the system equation (4) for the largest eigenvalue, $\lambda$ gives the weight vector $\mathrm{W}$.

Step 5. Formation of the Weighted Normalized Data Matrix(V)

This matrix gives a true comparable value of each attribute. Thus:

The resulting matrix is an $m \times n$ matrix.

$$
v(i, j)=w_{-} j^{*} n(i, j)
$$

Step 6. Generating the hypothetical best solution (HBS) and the hypothetical worst solution (HWS)

Figure 1 shows graphically the concept of HBS and HWS for two sample attributes. The hypothetical worst solution is also an imaginary solution, but with least optimal favorable values. In present case since 10 attribute $\mathrm{s}$ are to be compared with 10 alternatives(options) it is inevitable to use computer as calculations will be many and will be out of reach of manual calculations. Also graphically the solution is not possible to achieve.

Thus:

$$
\begin{aligned}
& H B S=A^{+} \\
& \max _{j=1, i=1 \ldots m^{v(i, j)}}^{\max } \max _{\left.j=2, i=1 \ldots m^{v(i, j) \ldots \ldots} j=n, i=1 \ldots m^{v(i, j)}\right]}^{\max } \\
& =\left[\begin{array}{lllll}
v_{1}^{+} & v_{2}^{+} & \ldots & \ldots & v_{n}^{+}
\end{array}\right]
\end{aligned}
$$




$$
\begin{aligned}
& H W S=A^{-} \\
& = \\
& {\left[j=1, i=1 \ldots m^{v(i, j)} \min _{\left.j=2, i=1 \ldots m^{v(i, j) \ldots \ldots} j=n, i=1 \ldots m^{v(i, j)}\right]}^{\min }\right.} \\
& =\left[\begin{array}{lllll}
v_{1}^{-} & v_{2}^{-} & \ldots & \ldots & v_{n}^{-}
\end{array}\right]
\end{aligned}
$$

In some cases, minimum of certain attributes, for example cost, weignt eı. may give HBS and vice versa for HWS.

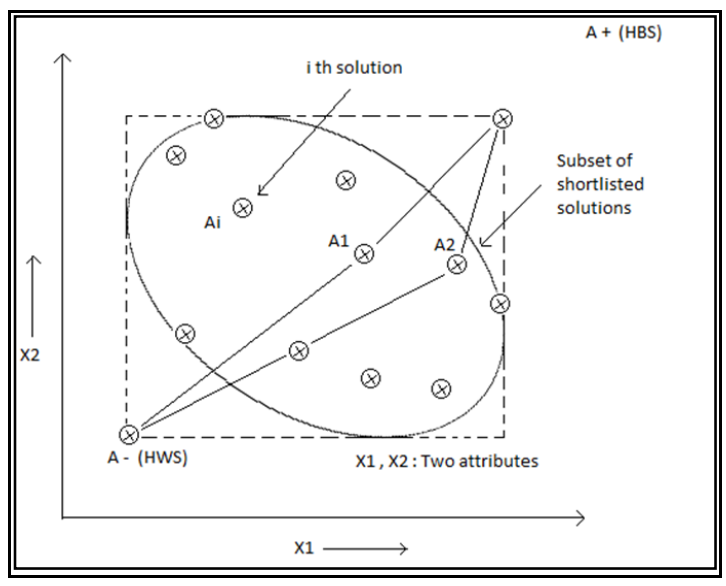

Fig.1 Graphical representation of HWS and HBS

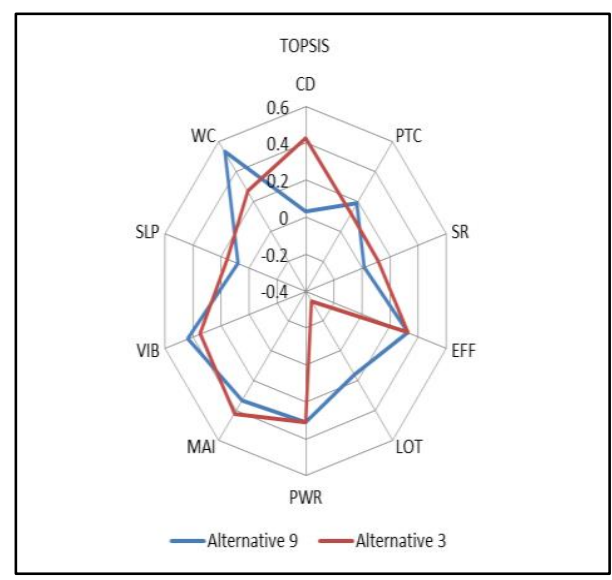

Fig.2 Radar Graph for best 2 alternatives

Step 7. Determining the Euclidean Distances

The distances are calculated as per below:

$$
\begin{aligned}
& S_{i}^{-}=\left\{\sum_{j=1}^{n}\left[v(i, j)-v_{j}^{-}\right]^{2}\right\}^{1 / 2} \\
& S_{i}^{+}=\left\{\sum_{j=1}^{n}\left[v(i, j)-v_{j}^{+}\right]^{2}\right\}^{1 / 2}
\end{aligned}
$$

Step 8. Determination of the Metric Index

The metric index is the relative closeness to the ideal solution, and is given by:

$$
m I=\frac{S_{i}^{-}}{S_{i}^{+}+S_{i}^{-}}
$$

It is a design evaluation index and simultaneously considers distances from the worst and the best solutions. Thus, resting on a much larger platform for comparison, the merit index is a true measure for $n$-attribute alternative design.

\section{Step 9. Establishing a Preference Order}

Referring to the Figure 1, it is apparent that if $A_{i}=A^{+}, S_{i}^{+}=0$ and $m I=1$. On the other hand, if $A_{i}=A^{-}, S_{i}^{-}=0$ and $m I=0$. This implies that the solution with the highest $m I$ value be 
given the highest rank, and so on. Thus, arranging in descending order of $m I$ values, a preference order is obtained.

\section{Step 10. Selection of the Optimum Design}

From the preference order, the design solution with the highest $m I$ value is the optimal alternative design for the given application.

This procedure will be of immense help to the manufacturer in resolving design conflicts and in making tradeoffs. Being scientific and objective, the algorithm has in-built application effectiveness and is thus helpful for making customized products resulting in enhanced customer satisfaction.

\section{RESULTS AND DISCUSSION}

The methodology is detailed in section IV. Tables 1,2,3 and 4 are intermediate calculated stepswhich are shown in Appendix. The highlighted values in the Table 4 are considered for radar graph as shown in Figure 2. The respective relative closeness of alternatives 1 to 10 to ideal solution is 0.3389 , $0.3333,0.4665,0.4566,0.4514,0.3411,0.3374,0.3718,0.4689,0.4449$. The relative closeness sorted is $0.4689,0.4665,0.4566,0.4514,0.4449,0.3718,0.3411,0.3389,0.3374,0.3333$. The order of preference of different alternatives is 9-3-4-5-10-8-6-1-7-2. The best alternative is 9. Figure 2 shows the comparative variations of different attributes for best two alternatives.

\section{CONCLUSION AND WAY FORWARD}

The application of TOPSIS method for the selection of optimum mechanical drives is presented. Upon application of the TOPSIS, the ranking of alternatives is obtained. The friction drive is ranked as first followed by flat belt drive,v-belt drive etc.Since the drive selection case is not attempted by any of the earlier researcher the validation of the present work is not possible here.However the approach presented would aid to existing method of selction as the TOPSIS is a scientific approach for optimum selection. Though the results are satisfactory, the designer can still have freedom to analyze the real life application and may increase the size of the data matrix. Additionally, many more MADM methods can also be tried.

\section{ACKNOWLEDGEMENT}

The encouragement and support provided by Sophisticated Instrumentation Center for Applied Research and Testing (SICART), an institute sponsored by Department of Science and Technology, Govt.of India, New Delhi jointly by Charutar Vidya Mandal, Vallabh Vidyanagar, Gujarat is highly appreciated and acknowledged.

\section{REFERENCES}

[1] R.V.Rao, Decision making in the manufacturing environment, Springer, 2007.

[2] Saaty T.L., The analytic hierarchy process, McGrow Hill, New York, 1980.

[3] Saaty T.L., Fundamentals of decision making and priority theory with the AHP, RWS publications, Pittsburg, 2000.

[4] Deng H., Yeh C.H., Willis R.J., Inter-company Comparison using Modified TOPSIS with objective weights, Computers and Operations

Research, 27, 963-973, 2002.

[5] Fishburn P C, Additive utilities with incomplete product set; applications to priorities and assignments, Operations research society of America, Baltimore, 1967.

[6] Ananthasuresh G.K., Ashby N.F., Concurrent Design in material selection for trusses, Notes of Workshop on optimal design, France, 26-28 Nov., 2003. 
[7] Abdalla S., Kizil M.S., Canbulat I., Development of a method for layout selection using analytical hierarchy process, 13th coal operators conference, University of Wollongong, Australia, pp.27-37, 14-15 Feb.2013

[8] Thirumalai R., Senthilkumar J.S., Intelligent selection of optimum machining parameters in turning of Inconel 718, International journal of advanced engineering technology, Vol.2, Issue 4, pp.167-173, Oct-Dec.2011.

[9] Zoran D., Sasa M., Dragi P., Application of the AHP method for selection of a transportation system in mine planning, Professional paper, Belgrade, Underground mining engineering, 19, 93-99, 2011.

[10] Dagdeviren M., Yavuz S., Kilinc N., Weapon selection using the AHP and TOPSIS methods under fuzzy environment, Journal of expert systems with applications, Elsevier, 36, pp.8143-8151, 2009.

[11] Chauhan A., Vaish R., Magnetic material selection using multiple attribute decision making approach, Journal of materials and design, Elsevier, 36, pp.1-5, 2012.

[12] S.C.Sharma, Agrawal, Machine Design. Kataria Publications, New Delhi 2010.

[13] R.Karwa, Machine Design. Laxmi Publications, New delhi, 2011

[14] T.G.Hicks, Machine Design Calculations Reference Guide, McGrawHill Publications, 1987.

[15] B.J.Hamrock, Bo Jacobson, S.R.Schmid, Fundamentals of Machine Elements, McGraw Hill Publications, 1999.

[16] J.E.Shigley, Co Mischke, R.G.Budinas, K.J.Nisbett, Mechanical Engineering Design, Tata McGraw Hill Publications, New Delhi, 1996.

[17] G.M.Maitra, L.V.Prasad, Handbook of Mechanical Design, Tata McGraw Hill Publications, New Delhi, 1997.

[18] www.reidsupply.com

[19] Yoon K P, Hwang C L, Multi-attribute decision making, SAGE publication, Beverley Hills, CA.

\section{APPENDIX}

Table 1 Data matrix for mechanical drives (10 drives, 10 attributes)

\begin{tabular}{|c|c|c|c|c|c|c|c|c|c|c|}
\hline Drives & $\begin{array}{l}\text { Lead } \\
\text { screw }\end{array}$ & $\begin{array}{l}\text { Ball } \\
\text { screw }\end{array}$ & $\begin{array}{l}\text { Flat } \\
\text { belt }\end{array}$ & $\begin{array}{l}\mathrm{V} \\
\text { belt }\end{array}$ & $\begin{array}{l}\text { Variable } \\
\text { speed } \\
\text { drive }\end{array}$ & $\begin{array}{l}\text { Roller } \\
\text { chain }\end{array}$ & $\begin{array}{l}\text { Silent } \\
\text { chain }\end{array}$ & $\begin{array}{l}\text { Rope } \\
\text { drive }\end{array}$ & $\begin{array}{l}\text { Friction } \\
\text { drive }\end{array}$ & $\begin{array}{l}\text { Gear } \\
\text { drive }\end{array}$ \\
\hline Attributes & (1) & (2) & (3) & (4) & & (6) & (7) & & & (10) \\
\hline $\begin{array}{l}\text { Centre Distance }(\mathrm{mm})(\mathrm{CD}) \\
(\mathrm{NB})\end{array}$ & 1000 & 1000 & 5000 & 500 & 2000 & 600 & 600 & 10000 & 300 & 800 \\
\hline $\begin{array}{l}\text { Power Trans. Capacity (kw) } \\
\text { (PTC) (B) }\end{array}$ & 300 & 150 & 125 & 190 & 100 & 250 & 250 & 750 & 200 & 500 \\
\hline Speed Ratio (SR) (B) & 0.3 & 2.5 & 80 & 150 & 150 & 25 & 25 & 25 & 15 & 600 \\
\hline Efficiency $(\%)(\mathrm{EFF})(\mathrm{B})$ & 45 & 98 & 96 & 95 & 96 & 99 & 99 & 96 & 95 & 80 \\
\hline $\begin{array}{l}\text { Lower Opg. Temp } \quad\left({ }^{0} \mathrm{c}\right) \\
(\mathrm{LOT})(\mathrm{NB})\end{array}$ & 20 & 20 & -40 & -55 & -40 & -20 & -20 & 55 & 20 & 60 \\
\hline $\begin{array}{l}\text { Power/Weight } \\
\text { (PWR) (B) }\end{array}$ & 0.6 & 0.65 & 0.8 & 0.7 & 0.75 & 0.95 & 0.9 & 1.2 & 0.80 & 0.6 \\
\hline $\begin{array}{l}\text { Maint.(poor-excellent:1-5) } \\
\text { (MAI) (B) }\end{array}$ & 3 & 4 & 5 & 5 & 3 & 3 & 3 & 4 & 4 & 3 \\
\hline $\begin{array}{l}\text { Vibrations.(high- } \\
\text { negligible:1-5) (VIB) (B) }\end{array}$ & 2 & 2 & 4 & 4 & 4 & 3 & 3 & 5 & 5 & 2 \\
\hline $\begin{array}{l}\text { Slip.(high-negligible:1-5) } \\
\text { (SLP) (B) }\end{array}$ & 5 & 5 & 2 & 3 & 3 & 5 & 5 & 4 & 1 & 5 \\
\hline $\begin{array}{l}\text { Working condition(worst- } \\
\text { good:5-1) (WC) (NB) }\end{array}$ & 3 & 2 & 4 & 4 & 4 & 5 & 5 & 4 & 2 & 2 \\
\hline
\end{tabular}

Table 2: Normalized Matrix 


\begin{tabular}{|l|l|l|l|l|l|l|l|l|l|l|}
\hline Alternative & CD & PTC & SR & EFF & LOT & PWR & MAI & VIB & SLP & WC \\
\hline 1 & 0.10 & 0.40 & 0.00 & 0.45 & -2.75 & 0.50 & 1.00 & 1.00 & 0.20 & 0.75 \\
\hline 2 & 0.10 & 0.20 & 0.00 & 0.99 & -2.75 & 0.54 & 0.75 & 1.00 & 0.20 & 0.75 \\
\hline 3 & 0.50 & 0.17 & 0.13 & 0.97 & 1.38 & 0.67 & 0.60 & 0.50 & 0.50 & 0.50 \\
\hline 4 & 0.05 & 0.25 & 0.25 & 0.96 & 1.00 & 0.58 & 0.60 & 0.50 & 0.33 & 0.50 \\
\hline 5 & 0.20 & 0.13 & 0.25 & 0.97 & 1.38 & 0.63 & 1.00 & 0.50 & 0.33 & 0.50 \\
\hline 6 & 0.06 & 0.33 & 0.04 & 1.00 & 2.75 & 0.79 & 1.00 & 0.67 & 0.20 & 0.25 \\
\hline 7 & 0.06 & 0.33 & 0.04 & 1.00 & 2.75 & 0.75 & 1.00 & 0.67 & 0.20 & 0.25 \\
\hline 8 & 1.00 & 1.00 & 0.04 & 0.97 & -1.00 & 1.00 & 0.75 & 0.40 & 0.25 & 0.50 \\
\hline 9 & 0.03 & 0.27 & 0.03 & 0.96 & -2.75 & 0.67 & 0.75 & 0.40 & 1.00 & 1.00 \\
\hline 10 & 0.08 & 0.67 & 1.00 & 0.81 & -0.92 & 0.50 & 1.00 & 1.00 & 0.20 & 0.50 \\
\hline
\end{tabular}

Table 3: Relative Importance Matrix

\begin{tabular}{|l|l|l|l|l|l|l|l|l|l|l|}
\hline Alternative & CD & PTC & SR & EFF & LOT & PWR & MAI & VIB & SLP & WC \\
\hline 1 & 1 & 0.34 & 0.5 & 0.23 & 0.75 & 0.5 & 0.34 & 0.5 & 0.14 & 0.34 \\
\hline 2 & 2.99 & 1 & 0.41 & 0.34 & 0.67 & 0.41 & 0.59 & 0.59 & 0.5 & 0.75 \\
\hline 3 & 2 & 2.44 & 1 & 0.5 & 0.75 & 0.67 & 0.5 & 0.67 & 0.26 & 0.95 \\
\hline 4 & 4.44 & 4.26 & 0.5 & 1 & 0.59 & 0.41 & 0.67 & 0.59 & 0.5 & 0.86 \\
\hline 5 & 1.34 & 1.5 & 1.34 & 1.69 & 1 & 0.14 & 0.26 & 0.67 & 0.41 & 0.5 \\
\hline 6 & 2 & 2.44 & 1.5 & 2.44 & 7.41 & 1 & 0.67 & 0.59 & 0.5 & 0.67 \\
\hline 7 & 2.99 & 1.69 & 2 & 1.5 & 3.92 & 1.5 & 1 & 0.5 & 0.5 & 0.67 \\
\hline 8 & 2 & 1.69 & 1.5 & 1.69 & 1.5 & 1.69 & 2 & 1 & 0.5 & 0.59 \\
\hline 9 & 7.41 & 2 & 3.92 & 2 & 2.44 & 2 & 2 & 2 & 1 & 0.67 \\
\hline 10 & 2.99 & 1.34 & 1.05 & 1.16 & 2 & 1.5 & 1.5 & 1.69 & 1.5 & 1 \\
\hline
\end{tabular}

Table 4: Normalized Decision Matrix

\begin{tabular}{|l|l|l|l|l|l|l|l|l|l|l|}
\hline Alternative & CD & PTC & SR & EFF & LOT & PWR & MAI & VIB & SLP & WC \\
\hline 1 & 0.09 & 0.28 & 0.00 & 0.16 & 0.16 & 0.23 & 0.25 & 0.18 & 0.39 & 0.4 \\
\hline 2 & 0.09 & 0.14 & 0.00 & 0.34 & 0.16 & 0.25 & 0.33 & 0.18 & 0.39 & 0.4 \\
\hline 3 & $\mathbf{0 . 4 3}$ & $\mathbf{0 . 1 2}$ & $\mathbf{0 . 1 2}$ & $\mathbf{0 . 3 3}$ & $\mathbf{- 0 . 3 3}$ & $\mathbf{0 . 3 1}$ & $\mathbf{0 . 4 2}$ & $\mathbf{0 . 3 5}$ & $\mathbf{0 . 1 6}$ & $\mathbf{0 . 2 7}$ \\
\hline 4 & 0.04 & 0.18 & 0.23 & 0.33 & -0.45 & 0.27 & 0.42 & 0.35 & 0.23 & 0.27 \\
\hline 5 & 0.17 & 0.09 & 0.23 & 0.33 & -0.33 & 0.29 & 0.25 & 0.35 & 0.23 & 0.27 \\
\hline 6 & 0.05 & 0.23 & 0.04 & 0.34 & -0.16 & 0.37 & 0.25 & 0.27 & 0.39 & 0.13 \\
\hline 7 & 0.05 & 0.23 & 0.04 & 0.34 & -0.16 & 0.35 & 0.25 & 0.27 & 0.39 & 0.13 \\
\hline 8 & 0.87 & 0.7 & 0.04 & 0.33 & 0.45 & 0.47 & 0.33 & 0.44 & 0.31 & 0.27 \\
\hline 9 & $\mathbf{0 . 0 3}$ & $\mathbf{0 . 1 9}$ & $\mathbf{0 . 0 2}$ & $\mathbf{0 . 3 3}$ & $\mathbf{0 . 1 6}$ & $\mathbf{0 . 3 1}$ & $\mathbf{0 . 3 3}$ & $\mathbf{0 . 4 4}$ & $\mathbf{0 . 0 8}$ & $\mathbf{0 . 5 3}$ \\
\hline 10 & 0.07 & 0.47 & 0.93 & 0.28 & 0.49 & 0.23 & 0.25 & 0.18 & 0.39 & 0.27 \\
\hline
\end{tabular}

